\title{
Violência de gênero e saúde coletiva: um debate necessário
}

\author{
Silvana Maria Escorsim \\ Faculdades Integradas do Brasil (Unibrasil) \\ Faculdade Pe. João Bagozzi
}

Violência de gênero e saúde coletiva: um debate necessário

Resumo: O trabalho discute a violência como um fenômeno humano-social, relacional, multicausal e polissêmico, complexo em sua origem e em suas manifestações, produzido sócio-historicamente. Debate a violência na política de saúde e destaca os avanços da Lei Maria da Penha. Apresenta alguns índices de violência contra as mulheres no Brasil, por meio de pesquisa realizada pelo Ministério da Saúde e reflete sobre a intersetorialidade das ações públicas.

Palavras-chave: Violência. Violência de Gênero. Política de Saúde. Política afirmativa de gênero.

\section{Gender Violence and Collective Health: a Necessary Debate}

Abstract: This study discusses violence as a social-human phenomenon that is relational, multi-causal and polysemic, complex in its origins and manifestations and socio-historically produced. It debates the treatment of violence by healthcare policy and highlights advances of the Maria da Penha Law for women who are victims of domestic violence. It presents data about violence against women in Brazil, from a study conducted by the Ministry of Health and reflects on the intersectorial nature of public actions.

Keywords: Violence. Gender violence. Healthcare policy. Gender affirmation policy. 


\section{Introdução}

O fenômeno da violência está presente no cotidiano da vida social, repleto de contradições, antagonismos e conflitos nas suas complexas formas de expressão. Comumente, a violência é interpretada como uma disfunção psíquica que acomete a saúde mental de indivíduos e grupos, o que os leva aos "desajustes sociais", naturalizando-a como fenômeno ordinário em diferentes sociedades. Contudo, se faz necessário compreendêla, desvelando as suas representações sobre o real que ocultam o seu caráter humano e sócio-histórico. O percurso do presente debate propõe dar visibilidade aos seus nexos internos, explicitando suas dimensões particulares e universais, constituídas em sociedades historicamente determinadas, como é o caso brasileiro, e a interface necessária entre as políticas de saúde e afirmativas de gênero como resposta estatal emergente para o enfrentamento da violência contra a mulher.

\section{Aproximação ao fenômeno da violência}

Cotidianamente, as notícias sobre os mais variados tipos de violência povoam os noticiários locais e nacionais como destaques da mídia falada e escrita, o que vem a corroborar a opinião pública de que a sociedade contemporânea divide-se entre os que praticam criminalidades e violências e aqueles a quem resta defender-se delas, num mundo cada vez mais belicoso.

Contudo, a representação social dessa condição imposta pelos atos de violência está impregnada de valorações de caráter maniqueísta que coloca agressores e vítimas em lados distintos e opostos. Tornou-se lugar comum explicá-los a partir da "maldade" latente que, supostamente, acometeria a psique de alguns indivíduos, sendo esta patológica e disfuncional ou por vezes, associada à crença religiosa de possessão espiritual, numa sociedade de normas e regras sociais bem estabelecidas. De qualquer modo, para o senso comum, estas condutas refletem-se nos chamados "desajustes sociais", que os classifica como fenômenos ordinários em diferentes sociedades.

Porém, a violência na sociedade manifesta-se como um paradoxo: há aquelas que são consensuadas e por isso, toleradas, como também, aquelas que são condenadas por extrapolarem a regra e a norma social instituída, impingindo um sentimento de repulsa coletiva. O exemplo mais contundente da primeira são as punições físicas e morais, por vezes violentas, na "educação das crianças" por seus pais ou responsáveis e nas brigas domésticas e conjugais. $\mathrm{Na}$ segunda, encontram-se os crimes cometidos com armas brancas ou de fogo que ferem ou retiram a vida das suas vítimas; estes últimos cada vez menos tolerados na sociedade contemporânea.

A violência exibe variadas faces; não é uniforme e nem tampouco homogênea. Ao mesmo tempo em que a extensão e o grau da atrocidade cometida pelo ato criminoso e violento condenam o agressor a extirpá-lo por meio dos mecanismos jurídico-legais da sociedade, a discriminação, o isolamento e a invisibilidade social marcam de forma silenciosa e eficaz a violência contra suas vítimas.

Este tipo de violência conduz gradativamente ao ostra-
A violência assumiu formas e conteúdos diversos em diferentes sociedades e contextos históricos. É um fenômeno que transcende ao tempo e ao espaço geográfico. Acomete diferentes culturas e classes sociais, ainda que seu impacto possa ser sentido com maior vigor nos grupos considerados vulneráveis e em países periféricos ao desenvolvimento capitalista mundial. cismo ou morte social de indivíduos e grupos considerados desviantes, improdutivos, desnecessários e, por isso, descartáveis sob a ótica das relações capitalistas de produção. Um exemplo concreto são as constantes violações de direitos, violências físicas, morais e psicológicas, que por vezes resultam em mortes, sofridas pela população em situação de rua nas grandes metrópoles.

A violência também se constituiu como objeto de mercantilização. A insegurança e o medo coletivo estimulam a criação e a opulência de um mercado de venda de bens e serviços de segurança, como equipamentos eletrônicos para residências e condomínios, blindagem de automóveis, seguros de vida pessoal, patrimonial 
e de segurança. Esses insumos restringem-se a uma camada da população com poder aquisitivo que pode isolar-se e proteger-se do mundo em seu entorno (MINAYO, 2005).

Também é oportuno mencionar o mercado paralelo das contravenções e crimes, sustentados pelo tráfico de drogas ilícitas, armamentos de fogo, contrabandos em geral, do qual participam outros segmentos sociais, produtores ou viabilizadores de ações criminosas e de violências em geral, que se ramificam em solo nacional com articulações internacionais.

Ainda que de modo equivocado, o senso comum atribui à saúde, ou neste caso, à falta dela, uma interlocução com a violência. A violência não se caracteriza como um objeto típico da assistência à saúde, contudo, seus impactos traduzidos nas lesões, danos físicos e emocionais, os traumas originários dos acidentes, atos violentos e mortes exigem dos profissionais e serviços uma atualização de seus saberes e uma reorganização de suas práticas. Do mesmo modo, no âmbito social, há exigência de políticas específicas (MINAYO, 2005) que conjuguem saúde, assistência social, previdência, educação e segurança pública.

Os serviços de saúde tradicionalmente foram estruturados para atender estados clínicos agudos, crônicos ou agravos que demandam procedimentos médicos e das demais áreas constitutivas da saúde; em síntese: "enfermidades de origem biomédica" (MINAYO, 2005, p. 12). Hoje, também são requisitados a dar providências aos impactos causados por acidentes e atos de violência.

"Os acidentes e violências configuram assim um conjunto de eventos e lesões que podem ou não levar a óbito, reconhecidos na Classificação Internacional das Doenças como causas externas" (MINAYO, 2009, p. 26). Apesar do reconhecimento da Organização Mundial da Saúde e das diretrizes emanadas do Ministério da Saúde do Brasil, nem sempre os serviços de saúde dispõem de pessoal qualificado, recursos materiais e estrutura física compatíveis para acolher essas demandas sociais.

\section{Como a violência pode ser compreendida?}

A violência assumiu formas e conteúdos diversos em diferentes sociedades e contextos históricos ${ }^{1}$. É um fenômeno que transcende ao tempo e ao espaço geográfico. Acomete diferentes culturas e classes sociais, ainda que seu impacto possa ser sentido com maior vigor nos grupos considerados vulneráveis e em países periféricos ao desenvolvimento capitalista mundial.

É um fenômeno humano e social pelo seu caráter relacional, multicausal e polissêmico, o que o torna complexo em sua origem e manifestações. "Ela não pode ser analisada nem tratada fora da sociedade que a produz em sua especificidade interna e em sua particularidade histórica" (MINAYO, 2005, p. 15). Assim, é um fenômeno eminentemente sócio-histórico (MINAYO, 2005). Com certeza, a formação social e histórica de um país ou região em suas relações políticas e econômicas internas e externas produzem as teias relacionais que explicam como uma sociedade a projeta em sua subjetividade, nas formas de consciência social e a sua materialização no cotidiano.

Ainda que heterogêneo e multicausal, há como conceituar a violência? Existem aspectos que são convergentes? Muitos pesquisadores têm analisado e discutido a violência ${ }^{2}$, sem admitir que haja uma conceituação única ou suficiente para defini-la. Porém, alguns aspectos convergem para o seu entendimento.

A luta pelo poder, a afirmação da autoridade, da superioridade, a vontade de domínio, de posse, seja do corpo, dos bens ou dos conhecimentos do outro e por consequência, dos conflitos estabelecidos nessas relações, podem resultar na sujeição, captura de força de trabalho, talentos e posses ou até no extermínio do outro.

A Política Nacional de Redução da Morbimortalidade por Acidentes e Violências ${ }^{3}$ designa que em relação a sua natureza "há diversas formas de expressão da violência: agressão física, abuso sexual, violência psicológica e violência institucional" (BRASIL, 2001, p. 3). O mesmo documento esclarece as terminologias utilizadas:

Abuso físico ou maus-tratos físicos - uso de força física que pode produzir uma injúria, ferida, dor ou incapacidade.

Abuso psicológico ou maus-tratos psicológicos - agressões verbais ou gestuais com o objetivo de aterrorizar, rejeitar, humilhar a vítima, restringir a liberdade ou ainda isola-la do convívio social.

Abuso sexual - ato ou jogo sexual que ocorre em relação hetero ou homossexual que visa estimular a vítima ou utiliza-la para obter excitação sexual e práticas eróticas e sexuais impostas por meio de aliciamento, violência física ou ameaças (BRASIL, 2001, p. 27).

A caracterização das manifestações da violência é de vital importância, na medida em que esta desnaturaliza as práticas cotidianas cristalizadas em relações sociais historicamente patriarcais, autoritárias, 
elitistas e conservadoras, como é o caso brasileiro, em especial, na violência de gênero (destaca-se a de homens contra mulheres), étnico-raciais (brancos contra negros, contra judeus, contra ciganos, indígenas e outros) e geracionais (adultos contra crianças, adolescentes e idosos).

\section{Prevenção e promoção nas normatizações da Política de Saúde e de Gênero no combate a violência}

No início do século 21 as taxas de criminalidade, acidentes e violências em todos os níveis cresceram exponencialmente, em especial, nas grandes metrópoles, tornando-se assunto emergente para os estados e municípios, que não conseguem dar respostas eficazes a população, tanto no que diz respeito à prevenção quanto na coerção do crime e da violência. Esta situação persistiu durante a primeira década, o que demonstra a obsolescência e ineficiência do tradicional sistema de segurança pública brasileiro frente às configurações e expressões destas práticas.

Naquela ocasião, os resultados levantados pelos indicadores do Sistema Único de Saúde (SUS) no Brasil eram alarmantes. Segundo dados apresentados por Minayo (2005, p. 12), "no ano de 2000, o número de pessoas que procuraram os serviços hospitalares referenciados para o tratamento de traumas e lesões advindas de acidentes e violências foi de 693.961". Desse total, 38,3\% corresponderam aos homicídios (mortes por causas externas), sendo que $70 \%$ deles foram provocados pelo uso de armas de fogo. O impacto mais significativo desse crescimento deu-se no aumento dos gastos com o atendimento emergencial em saúde, na recuperação e na reabilitação dos pacientes atendidos.

Diante desse cenário, o Ministério da Saúde instigou o debate junto aos conselhos municipais e estaduais de saúde, como também no Conselho Nacional de Saúde (MINAYO, 2009). O resultado materializou-se na publicação da Portaria n. 737/2001, chamada de Política Nacional de Redução da Morbimortalidade por Acidentes e Violência. O documento conceitua violência no sentido de orientar os serviços de saúde para o planejamento de ações em todos os níveis de gestão do sistema: "consideram-se como violências, ações realizadas por indivíduos, grupos, classes, nações que ocasionam danos físicos, emocionais e espirituais a si próprios e aos outros" (BRASIL, 2001, p. 7).

O Ministério da Saúde avançou ao situar a violência no centro da discussão como fenômeno a ser compreendido, diagnosticado e tratado adequadamente por profissionais e serviços de saúde em seus aspectos preventivos, os quais visam "diminuir os impactos dos fatores de risco, tratar das disfunções ou agravos identificados, como também impedir que os indivíduos sejam acometidos por novas enfermidades" (BUSS, 2003, p. 33). Mas, fundamentalmente, inovou ao inseri-lo no campo da promoção da saúde, o qual entende que todos os seres humanos devem ter acesso a elevadas condições de desenvolvimento social e de saúde, como direito social, sendo esta uma responsabilidade primordial das políticas governamentais.

A promoção da saúde vem sendo objeto de debates há quase três décadas nas conferências internacionais promovidas pela Organização Mundial da Saúde, as quais referendam a perspectiva da cidadania: “A Promoção da Saúde fundamenta-se neste direito e tem por base um conceito positivo e inclusivo da saúde, como um determinante da qualidade de vida, incluindo-se o bem-estar mental e espiritual" (CARTA DE BANGKOK, 2005, p. 1).

Dentre as muitas expressões da violência, aquela que tem persistido como fenômeno histórico e universal é a de gênero, em particular de homens contra mulheres, configurando-se como transversal a questão de raça, etnia, faixa etária ou classe social. Hoje é considerada uma questão de saúde pública e uma violação aos direitos humanos. Suas várias formas de opressão, de dominação e de crueldade incluem assassinatos, estupros, abusos físicos, sexuais e emocionais, prostituição forçada, mutilação genital, violência racial e outras. "Os perpetradores costumam ser parceiros, familiares, conhecidos, estranhos ou agentes do Estado" (GOMES [et al.] apud MINAYO, 2009, p. 36).

O marco histórico na legislação brasileira que inaugura um sistema de enfrentamento a violência doméstica e familiar contra a mulher é, sem dúvida, a Lei Maria da Penha ${ }^{4}$ conquistada por meio da mobilização de várias entidades não governamentais e movimentos feministas ${ }^{5}$ que endossaram a luta e a perseverança da cidadã Maria da Penha Maia Fernandes para que a justiça punisse o seu agressor (CORRÊA, 2011). Esta luta singular expressava a realidade coletiva de milhares de brasileiras, igualmente vitimadas e que não encontravam amparo no poder público.

A Lei respondeu à histórica condição de opressão, subjugação e violência contra a mulher, resultado de uma cultura conservadora fundamentada em padrões androcêntricos, patriarcais e sexistas que reafirmava a desigualdade e naturalizava a discriminação e a violência como construções sócio-culturais, nas quais a intolerância, o desrespeito e a impunidade tinham lugar preservado no contexto das relações intrafamiliares. Anteri- 
ormente à Lei, no caso de denúncia, a violência doméstica era banalizada pelos Juizados Especiais Criminais, cuja medida adotada junto ao agressor "culminava no pagamento de cestas básicas e outras penas alternativas que raramente eram cumpridas" (CORRÊA, 2011, p. 42). A Lei Maria da Penha prevê medidas protetivas e de urgência a serem requeridas no ato do registro da ocorrência junto às delegacias de polícia ou Ministério Público, tais como: proteção policial, atendimento médico (legista), de equipe multiprofissional, transporte e abrigamento em local seguro da vítima e de seus dependentes, bem como a prestação de informações sobre os direitos que lhe são assegurados pela Lei.

Desde 2006, os serviços referenciados pelo SUS utilizam à notificação de violência doméstica, sexual e/ou outras violências. Esta é contínua e tem caráter compulsório nas situações que envolvam crianças, adolescentes, mulheres e idosos. Está prevista no Estatuto da Criança e do Adolescente (ECA) ${ }^{6}$ e no Estatuto do Idoso ${ }^{7}$ e, no caso das mulheres, a notificação de violência está amparada na Lei n. 10.778/2003 (BRASIL, 2003b).

Como instrumento, amplia a coleta de dados para a epidemiologia ${ }^{8}$, porém seu alcance social está em garantir direitos, preservar a saúde e a vida, além de municiar a rede de proteção social e de atenção integral a saúde.

A partir das notificações, a Vigilância de Violências e Acidentes (Viva) da Secretaria de Vigilância em Saúde, Departamento de Análise de Situação em Saúde do Ministério da Saúde, produziu uma pesquisa durante os anos 2008 e 2009 nas capitais e Distrito Federal ${ }^{9}$ e realizou várias análises dentre todas as informações coletadas. Quanto à violência contra a mulher, obteve os seguintes resultados:

\section{1) Casos de violência notificados por sexo:}

\begin{tabular}{l|c|c}
\hline \multicolumn{1}{c|}{ Sexo } & f & \% \\
\hline Mulheres & 6.236 & 71,1 \\
\hline Homens & 2.530 & 28,9 \\
\hline Total & 8.766 & 100,0 \\
\hline
\end{tabular}

Fonte: BRASIL (2010).

Os resultados demonstram que as mulheres constituem o grupo social mais atingido pela violência, com 6.236 casos notificados no período estudado.

2) Distribuição por faixa etária nas ocorrências de violência contra mulheres:

\begin{tabular}{|l|c|c|}
\hline \multicolumn{1}{|c|}{ Faixa etária } & f & \% \\
\hline 0 a 9 anos & 1.309 & 21,0 \\
\hline $\mathbf{1 0}$ a 19 anos & 1.796 & 28,8 \\
\hline $\mathbf{2 0}$ a 29 anos & 1.241 & 19,9 \\
\hline Acima dos 30 anos & 1.890 & 30,3 \\
\hline Total & 6.236 & 100,0 \\
\hline
\end{tabular}

Fonte: BRASIL (2010).

Pode-se observar que a faixa etária feminina mais suscetível à violência encontra-se nas mulheres préadolescentes, adolescentes e adultas jovens entre 10 e 19 anos (28,8\%), seguidas por crianças na faixa de até 9 anos (21\%). Estes indicadores permitem inferir o agravamento do quadro de violência contra as mulheres no Brasil, no qual crianças e adolescentes femininas são diariamente vitimizadas.

Por fim, a pesquisa do órgão demonstrou que nas mulheres, a maior ocorrência foi da agressão física (52\%), seguida da violência psicológica/moral (49,5\%) e sexual (39\%). A expressão da violência é sempre composta por vários atos acintosos que intencionam submeter, prejudicar ou causar dano as suas vítimas de várias formas possíveis, portanto, sua materialização se dá num conjunto de eventos e atos.

Apesar das conquistas e avanços sociais garantidos pela Lei Maria da Penha, a violência doméstica e familiar continua sendo uma amarga realidade para muitas mulheres no Brasil. Contudo, há que se considerar que o incremento dos números apontados pelas estatísticas podem também demonstrar o aumento das denúncias pela popularização da Lei e pela vocalização contínua dos movimentos da sociedade civil organizada, em especial, do Movimento de Mulheres. Este último tem sido protagonista na luta para a garantia e efetivação das medidas 
protetivas e de urgência, previstas em lei, junto aos órgãos do poder público que são os responsáveis em prevenir, proteger e coibir a violência doméstica e familiar, como também as suas demais formas de expressão.

Como problema de saúde coletiva, a violência deve ser objeto da política de saúde em duas dimensões: a primeira, na operacionalização das ações em saúde, que se reflete no cuidado e na assistência prestada. Para tanto, são essenciais os protocolos preventivos (primários, secundários e terciários), a capacitação continuada dos profissionais, a criação, a ampliação e a melhoria dos recursos e equipamentos referenciados do SUS.

A segunda dimensão diz respeito às políticas de promoção da saúde, na articulação dos vários ministérios e órgãos do governo, tais como saúde, educação, previdência, segurança pública e políticas para as mulheres, a fim de estimular conhecimentos, debates e ações sobre o tema em toda a sociedade.

Os caminhos a serem eleitos demandam construções coletivas de novas práticas e formas de expressão da cultura popular, baseadas no respeito à diversidade social e tolerância frente às diferenças de gênero, étnico-raciais e geracionais. Isto significa ampliar o campo de atenção da violência como fenômeno social não restrito ao campo punitivo da segurança pública, como vem sendo tratada até o momento. Como fenômeno construído sócio-historicamente, está organicamente vinculado com as múltiplas expressões da questão social no bojo das relações econômico-sociais do desenvolvimento capitalista contemporâneo.

\section{Considerações finais}

A compreensão das múltiplas expressões da violência, como fenômeno humano-social, requer uma análise profunda da sociedade que as produz em suas particularidades, no que se refere a sua formação social e econômica e de universalidade sócio-histórica.

Enquanto particularidade histórica e social, o Brasil vem registrando indicadores alarmantes com relação às lesões, mortes e agravos causados por acidentes e violências, cujos impactos repercutem nos serviços de urgência/emergência, tornando-se um problema de saúde coletiva. Neste contexto, destaca-se o crescimento da violência contra a mulher e, em especial, no segmento das crianças e adolescentes femininas, o que exige uma ampla mobilização das políticas públicas, com a articulação de suas redes e serviços para a prevenção, atendimento, proteção e reabilitação de suas vítimas, o que se configura na atualidade como um imenso desafio a ser transposto.

Assim, as respostas estatais por meio das políticas públicas serão efetivas na medida em que privilegiem a intersetorialidade das ações na construção de redes de atenção, câmaras técnicas, como também junto aos conselhos de direitos, nos quais a população seja chamada ao papel de protagonista para debater, deliberar e construir novas sociabilidades em defesa da vida e da emancipação humana.

\section{Referências}

BRASIL. Lei n. 8.069, de 13 de julho de 1990. Dispõe sobre o Estatuto da Criança e do Adolescente e dá outras providências. 1990. Disponível em: <http://www.planalto.gov.br/ccivil_03/leis/18069.htm>. Acesso em: 7 abr. 2013.

. Ministério da Saúde. Portaria GM/MS n. 737, de 16 de maio de 2001. Diário Oficial da União, n. 96. Seção 1e, 18 de maio de 2001. Disponível em: <http://portal.saude.gov.br/portal/arquivos/pdf/portaria737.pdf>. Acesso em: 7 abr. 2013.

. Lei n. 10.741, de $1^{\circ}$ de outubro de 2003. Dispõe sobre o Estatuto do Idoso e dá outras providências. 2003a. Disponível em: <http://www.planalto.gov.br/ccivil_03/leis/2003/110.741.htm>. Acesso em: 7 abr. 2013.

. Lei n. 10.778, de 24 de novembro de 2003. Estabelece a notificação compulsória, no território nacional, do caso de violência contra a mulher que for atendida em serviços de saúde públicos ou privados. 2003b. Disponível em: <http://www.planalto.gov.br/ ccivil_03/leis/2003/110.778.htm>. Acesso em: 7 abr. 2013.

. Lei n. 11.340, de 7 de agosto de 2006. Cria mecanismos para coibir a violência doméstica... Disponível em: <http:// www.planalto.gov.br/ccivil_03/_ato2004-2006/2006/lei/111340.htm>. Acesso em: 7 abr. 2013.

. Ministério da Saúde. Secretaria de Vigilância em Saúde. Departamento de Análise de Situação em Saúde. Viva: Vigilância de Violências e Acidentes, 2008 e 2009. Brasília: Ministério da Saúde, 2010.

BUSS, P. M. Uma introdução ao conceito de promoção da saúde. In: CZERESNIA, D.; FREITAS, C. M. de (Org.). Promoção da saúde: conceitos, reflexões, tendências. Rio de Janeiro: Ed. da Fiocruz, 2003, p. 15-38.

CARTA DE BANGKOK. In: VI CONFERÊNCIA INTERNACIONAL DE PROMOÇÃO DA SAÚDE. Bangkok, Tailândia, 2005. Disponível em: <http://www.bvsde.ops-oms.org/bvsdeps/fulltext/cartabangkokpor.pdf>. Acesso em: 7 abr. 2013.

CHESNAIS, J. C. Histoire de la violence em Occident de 1800 a nos jours. Paris: Robert Laffont Editor, 1981.

CORRÊA, R. C. (Org.). O enfrentamento à violência doméstica e familiar contra a mulher: uma construção coletiva. Conselho Nacional de Procuradores-Gerais, 2011. 
DOMENACH, J-M. La violencia. In: UNESCO (Org.). La violencia y sus causas. Paris: Unesco, 1981, p. 33-45.

FOUCAULT, M. Vigiar e punir: nascimento da prisão. Tradução de Raquel Ramalhete. Petrópolis: Vozes, 2000.

MINAYO, M. C. de S. Violência: um problema para a saúde dos brasileiros. In: BRASIL, Ministério da Saúde. Secretaria de Vigilância em Saúde. Impacto da violência na saúde dos brasileiros. (Série B. Textos Básicos de Saúde). Brasília: Ministério da Saúde, 2005, p. 9-41.

Conceitos, teorias e tipologias de violência: a violência faz mal à saúde. In: NJAINE, K. [et al.] (Org.). Impactos da violência na saúde. Rio de Janeiro: Fundação Oswaldo Cruz; Educação à distância da Escola Nacional de Saúde Pública Sérgio Arouca, 2009, p. 21-42.

ROUQUAYROL, M. Z. Contribuição da epidemiologia. In: CAMPOS, G. W. de S. [et al.] (Org.). Tratado de saúde coletiva. São Paulo: Hucitec; Rio de Janeiro: Ed. da Fiocruz, 2009, p. 319-373.

\section{Notas}

1 Tanto as práticas quanto as formas de violência em ato ou em sua punição assumiram diferentes conteúdos. Foucault em sua obra Vigiar e punir: nascimento da prisão (2000) relata que cada época instituiu os mais variados processos punitivos, desde a violência física, no suplício do corpo ao uso dos institutos penitenciários modernos.

2 Pode-se citar Domenach (1981) e Chesnais (1981); no Brasil a profícua reflexão de Minayo (2005; 2009).

3 Portaria GM/MS n. 737, de 16 maio de 2001 (BRASIL, 2001).

4 Lei n. 11.340, de 7 de agosto de 2006 (BRASIL, 2006).

5 Corrêa (2011, p. 14) cita as seguintes entidades: "Cidadania, Estudo, Pesquisa, Informação e Ação (Cepia); Centro Feminista de Estudos e Assessoria (Cfemea); Gênero, Cidadania e Desenvolvimento (Agende); Defesa de direitos (Advocaci); Comitê Latino-Americano e do Caribe para a Defesa dos Direitos da Mulher (Cladem); Instituto para a Promoção da Equidade (IPÊ); Assessoria Jurídica e Estudos de Gênero (Themis)."

6 Lei n. 8.069, de 13 de julho de 1990 (BRASIL, 1990).

7 Lei n. 10.741, de $1^{\circ}$ de outubro de 2003 (BRASIL, 2003a).

8 Rouquayrol (2009, p. 321) define como "Ciência que estuda o processo saúde-doença em coletividades humanas, analisando a distribuição e os fatores determinantes das enfermidades, danos à saúde e eventos associados à saúde coletiva, propondo medidas específicas de prevenção, controle, ou erradicação de doenças, e construindo indicadores que sirvam de suporte ao planejamento, administração e avaliação das ações de rotina, em consonância com as políticas de promoção da saúde".

9 BRASIL (2010).

\section{Silvana Maria Escorsim}

mariaescorsim@uol.com.br

Doutora em Serviço Social pela Pontifícia Universidade Católica de São Paulo (PUC-SP)

Docente do curso de Serviço Social das Faculdades Integradas do Brasil (Unibrasil)

Coordenadora do curso de Serviço Social da Faculdade Pe. João Bagozzi

\section{Unibrasil}

Rua Konrad Adenauer, 442

Curitiba - Paraná - Brasil

CEP: 82820-540 